Roger M Pinder

York, UK

\section{International Journal of Wine Research}

Starting a new journal is generally a difficult, brave and sometimes foolhardy pursuit. Finding publishers, appointing editors, recruiting editorial board members, calling for manuscripts, selecting peer reviewers who will deliver on time and finding substitutes when they do not, and all of this initially without accreditation at the major medical indices, which makes authors understandably reluctant to commit their best work when it cannot be cited yet. The International Journal of Wine Research (IJWR) is no exception, but it did have the advantage that the publisher Dove Medical Press was more than willing to promote a new journal in this important and growing area of science.

Wine science is on a roll. It has become the stuff of the popular press, magazines, radio, television, and the Internet. Not a week goes by without some report of yet another important beneficial or harmful effect of wine or alcohol on human health. Genetic engineering of the grapevines that we know and love is now possible, a process that has already been applied vigorously to improve the properties of the yeasts used in fermentation. We do well to remember that many of the noble varietals - Cabernet Sauvignon, Syrah, Chardonnay - are themselves products of centuries-old natural genetic modification.

IJWR will provide a platform for the publication of evidence-based studies on all scientific aspects of wine including the growing of vines (viticulture), wine elaboration (enology), human interaction with wine, and the health aspects of wine. It is a peerreviewed, open access journal intended to maintain the highest possible global scientific standards. In addition to the usual reviews, original research papers and case reports that appear in this first volume, we will also publish commentary and expert opinion. To achieve these goals, this first issue includes publications from Europe (Czech Republic, France, Italy, Spain, Switzerland, and the UK), the Americas, Africa (Nigeria), Australia, and the Far East (China). They cover all four of our main areas: grape and vine analysis, yeasts, wine rating scales, environmental choices, the wine business, antioxidant activity, and wine and dementia.

I wish to thank the members of our editorial board, peer reviewers, authors, and Dove Medical Press for their tremendous help in preparing this inaugural issue. 